\title{
AUTORÍAS SUBTERRÁNEAS. TEXTO, CUERPO Y VIDA EN TIME HAS FALLEN ASLEEP IN THE AFTERNOON SUNSHINE ${ }^{1}$
}

Victoria PÉREZ ROYO

Universidad de Zaragoza

vicpr@unizar.es

Todo sueño es una profecía. Toda broma una intención seria en la matriz del tiempo. Father Keegan, 1904

El destino de todo libro es misterioso, sobre todo para su autor.

Alberto Manguel, 1996

$\mathrm{E}$ n su obra maestra de seis volúmenes Nor-noroeste, Ramón Bonavena describe con precisión extrema la esquina de su escritorio. Su exactitud es tal que tan sólo la descripción de su lápiz le lleva veintinueve páginas. Lambkin Formento, con una minuciosidad similar aplicada a otro ámbito, fue el creador de un tipo de crítica literaria que definió como perfecta: una que coincide palabra por palabra con el poema analizado. Así era su crítica de La divina comedia, un texto que encajaba exactamente con el original. Nierenstein Souza era un autor de textos muy particular: asumiendo el carácter cambiante de la literatura oral, decidió dejar de escribir y dedicarse a contar historias. No importaba si eran buenas o malas, ya que las sucesivas narraciones y el tiempo se encargarían de seleccionarlas, mejorarlas y de llevar a papel aquellas que merecieran la pena.

Estas son algunas de las fantasías literarias que Jorge Luis Borges y Adolfo Bioy Casares inventaron en su libro inolvidable Crónicas de Bustos Domecq (1967). Entre ellas, las últimas páginas de Fahrenheit 451 (1953) de Ray Bradbury podrían haber sido incluidas sin mayor problema: la descripción de una sociedad de individuos distribuidos por el país y conectados entre sí, cada uno de cuyos miembros ha memorizado un libro palabra por palabra. Aunque el contexto en el que ambos libros fueron escritos y las intenciones que subyacen a ellos difieren sustancialmente, merece la pena vincularlos para crear un posible marco a través del cual pensar acerca del proyecto Time has fallen

\footnotetext{
${ }^{1}$ El presente artículo es resultado de una investigación llevada a cabo en los últimos tres años. Pero en un nivel más profundo tiene que ver con cuestiones personales que suelen permanecer silenciadas detrás del texto y que en este caso hago manifiestas. Estas páginas, como todas las otras que he escrito, le deben muchísimo, casi todo, a mi padre: la curiosidad intelectual, la pasión por la literatura, el interés por explorar prácticas artísticas que transitan entre diferentes territorios, además de su inestimable apoyo en todos los niveles (personal, vital o académico, entre otros) a mi trabajo como investigadora. Gracias una vez más, gracias siempre.
} 
asleep in the afternoon sunshine (2010-...) de la artista Mette Edvardsen, en el que realiza la utopía de Bradbury: un número creciente de personas se dedica a la tarea individual de memorizar un libro de su elección. Esta actividad se presenta y desarrolla fundamentalmente en los diferentes festivales y eventos internacionales a los que el proyecto es invitado, de modo que se practica de forma intermitente, con periodos intensos de aprendizaje durante las semanas de residencia. Por el momento hay más de treinta libros vivos en lenguas como el inglés, francés, holandés, noruego, árabe, o griego, entre otras. Durante el festival, los participantes del proyecto, los libros vivos, se encuentran en una librería o biblioteca, memorizando sus textos respectivos y preparados para ser leídos por algún visitante, esto es, para recitarle las páginas o capítulos que hayan aprendido hasta ese momento. El proyecto a lo largo de los siete años en los que se lleva desarrollando ha pasado por diferentes fases: la primera, que continúa hasta hoy, está dedicada a la memorización. La segunda, que se desarrolla de manera ocasional, es la que se ha llamado segunda generación, que consiste en el traspaso del texto memorizado a otra persona que lo quiera aprender, sin mediación del objeto material libro. La última, que lleva en proceso desde 2016, consiste en devolver los libros al papel, con la particularidad de que el texto que se vuelca no es el original, sino el que se recuerda, el que ha vivido unos años en el cuerpo de quien lo aprendió, pasando por un proceso de memorización y una serie de recitados/lecturas.

Time has fallen ... se sitúa en un lugar inestable y complejo, muy interesante, entre la literatura y las artes del cuerpo, entre el texto escrito y su encarnación, entre la existencia tranquila del libro como objeto material inerte y sus vidas y aventuras en un cuerpo vivo, entre una existencia confirmada en papel y otra vicaria, invisible y opaca en un organismo en continua transformación. Time has fallen... replantea la literatura tal y como la conocemos mediante una rearticulación de los términos texto, cuerpo y vida, poniendo así de manifiesto una dimensión desatendida en los estudios literarios, quizá por su invisibilidad y difícil acceso: los procesos de transformación y de vida del texto en el proceso de su incorporación por parte del lector.

Hay tres figuras con las que se puede pensar esta la singular configuración entre cuerpo, vida y libro que se juega en Time has fallen... Las dos primeras, son de la tradición: el hafiz, la persona que ha aprendido de memoria el Corán y puede recitarlo a partir de cualquier punto; el copista medieval, por cuyas manos han ido viajando y sobreviviendo los libros a lo largo de la historia antes de la invención de la imprenta. La última es ficcional, es la figura del singular autor Pierre Menard, quien se propone escribir (no copiar, ni reproducir) El Quijote palabra por palabra.

\section{El hafiz y su memoria}

El aprendizaje de memoria quizá sea la mejor lectura posible de un libro, la del lector conmovido y fascinado, dispuesto a aprender el texto, de modo que se integre totalmente en su organismo vivo. Jean Racine, según se cuenta, memorizó la novela Las etiópicas o Teágenes y Cariclea para poder disfrutar a placer de sus escenas épicas y amorosas sin temor a que los clérigos jansenistas del internado en el que vivía echaran al fuego los sucesivos ejemplares que le habían encontrado leyendo. No se 
memoriza un libro cualquiera, sino alguno que ha causado especial conmoción. De hecho, la mayoría de colaboradores de Time has fallen... ha optado por aprender uno que ya estaba alojado en sus cuerpos, que había encontrado un buen lugar para quedarse, que había sido apropiado en parte ya antes de comenzar con el esfuerzo de su memorización. De hecho, las maneras en las que el libro se aloja en el cuerpo son fundamentales, como se sugiere en Elias of het gevecht met de nachtegalen de Maurice Gilliams de Wouter Krokaert (2016) en relación a la manera en la que las imágenes que se evocan en el texto se habían mezclado con las de su propia infancia.

El libro que probablemente se haya memorizado más sea el Corán, aprendido por millones de personas parcial o totalmente desde Mahoma en adelante. A quien conozca y pueda recitar sus 114 azoras (o capítulos), sus más de 6000 versos, se le otorga el título de hafiz, un gran reconocimiento en la cultura islámica, que puede colocar con orgullo delante de su nombre. Es muy significativo que una de las traducciones literales de hafiz sea guardián. El hafiz no sólo tiene que haber memorizado el Corán, sino también asegurarse de no olvidarlo, de modo que se dedica a lo largo de su vida a una práctica constante para guardar fidelidad a cada palabra exacta. Se trata de un proceso de vigilancia que se aplica tanto sobre el texto, como sobre el cuerpo que lo memoriza: a la obra se le impone una rigurosa disciplina que evita sus posibles alteraciones y transformaciones a través de los procesos de incorporación y vida. El cuerpo también es sometido en el esfuerzo ímprobo por recordar siempre de la misma manera. Pero el carácter indómito de lo corporal ha impedido su completa docilidad: aunque el texto se pueda conservar intacto, no se ha podido evitar el brote de una decena de escuelas de recitaciones distintas.

Los colaboradores de Time has fallen... son una especie un tanto extraña de hafices: han aprendido con todo el rigor posible sus libros respectivos, se han esforzado en preservarlos en su memoria de manera precisa, palabra por palabra, a lo largo de estos años. En ese proceso el libro ha comenzado a vivir de forma en parte incontrolable dentro de sus cuerpos, entremezclándose con recuerdos e imágenes, contaminándolos, apareciendo en los momentos más impredecibles. Esta intrusión recuerda en parte a otra de las ficciones de Borges, esta vez La memoria de Shakespeare (1983). Hermann Soergel es un experto en dramaturgia inglesa a quien se le ofrece un regalo imprevisto, poseer la memoria de Shakespeare, el cual acepta casi sin dudarlo. Aunque al comienzo busca imágenes claras que le puedan acercar al autor inglés, el carácter elusivo de la memoria no le permite hallarlas. Con el tiempo aprende a esperar su aparición, a descubrir recuerdos en sueños, o a dejar que le sorprenda en acciones cotidianas, como silbar una melodía desconocida o encontrarse diciendo palabras extrañas. Poco a poco, la memoria de Shakespeare se va infiltrando en la de Soergel, se superpone, la esconde y la transforma, hasta que el proceso acaba convirtiéndose en una amenazante invasión: la memoria de Shakespeare es tan poderosa que Soergel comienza incluso a olvidar su lengua materna, lo que le hace temer por su propia identidad y buen sentido y finalmente le conduce a pasar esa memoria a alguien desconocido. Los libros vivos de Time has fallen ... no llegan a tales extremos, pero en esta historia de Borges se encuentran similitudes con el proceso de adaptación y transformación a la que el texto memorizado somete a quien lo aprende. Por ejemplo, Mette Edvardsen me comentó 
que el lenguaje del libro que está memorizando, I am a cat de Soseki Natsume, había contaminado en parte su sintaxis ${ }^{2}$. O Rhiannon Newton explicaba cómo las imágenes de Orlando aparecen de forma recurrente en su mirada cotidiana.

La transformación no ocurre sólo en el cuerpo en relación al tex to que lo habita, sino que también se da en el otro sentido: el libro memorizado también se ve alterado en contacto con un cuerpo. Se trata de un proceso que se podría pensar casi como una transustanciación: mientras el libro material se va desintegrando físicamente por el uso excesivo ${ }^{3}$, va encontrando otro medio en el que alojarse, un cuerpo vivo. Cuando el texto se devuelve al papel se pueden observar las transformaciones que ha sufrido en él, dando así acceso a una dimensión de la literatura que se podría llamar la lectura después de la última página, la cual quizá el profesor Uzzi-Tuzii en Si una noche de invierno un viajero de Italo Calvino pueda definir bien: «una lengua sin palabras, con la que no se pueden escribir libros, pero que se puede sólo vivir, segundo a segundo, no registrar ni recordar» (Calvino, 1980: 34) Hasta ahora no se atendido a esta lengua, porque está en proceso continuo de cambio y porque no deja huella visible sobre el papel. Es la lengua en la que hablan los libros cuando se encarnan. Time has fallen... se esfuerza en dilatar los límites de la literatura en contacto con el cuerpo y en habitarlos, prestando atención a lo que usualmente se ha dejado al margen, a pesar de que está determinada por ello desde su misma raíz. Es una literatura imposible, que sólo se ha concebido en la ficción, en la literatura cimeria tal y como la describe Uzzi-Tuzii: una literatura hecha de libros inacabados, es la que conduce a «la otra lengua, [...] la lengua silenciosa a la cual remiten todas las palabras de los libros que creemos leer» (Ibíd.).

Los libros reescritos de Time has fallen..., producto de una lectura y una reescritura que no ignoran u ocultan su paso por el cuerpo, apuntan a lo que el libro dice, pero también a lo que no dice, apuntan a «un aliento interno siempre a punto de dispersarse en contacto con el aire» (Ibíd.: 33) Se trata de todo lo que implica la lectura de un libro que, en su materialidad aparentemente cerrada y sólida, da lugar siempre a una experiencia mucho más etérea que es de hecho la que mueve, guía y conforma toda lectura. El texto se convierte, en contacto con el cuerpo, dentro de su estabilidad visible, en un espacio invisible de múltiples dimensiones de reescritura y metamorfosis, que «restituyen al lenguaje escrito su energía activa» (Barthes, 1974: 142) y obtenida gracias a la lengua del cuerpo, de lo vivo, en contacto con el lenguaje escrito.

Para observar cómo se hace patente esa particular forma de literatura en Time has fallen... es necesario atender a la condición de copistas de los participantes del proyecto.

\footnotetext{
2 Todos los comentarios y anécdotas relatados de los participantes del proyecto han sido recogidos durante mi estancia en las tres semanas de residencia del proyecto en el Kunsten Festival des Arts (Bruselas), del 6 al 27 de mayo de 2017.

${ }^{3}$ No deja de resultar significativo que, aun siendo una experiencia común a todas las personas que han aprendido libros de memoria en este proyecto, yo escuchara esta anécdota de la desintegración del libro a medida que se aprende por parte de quien había memorizado La metamorfosis de Franz Kafka.
} 


\section{El copista y sus errores}

Si algunos textos clásicos de la antigüedad griega y romana, o los escritos que finalmente han conformado la Biblia, si una parte de los libros anteriores a la aparición de la imprenta han llegado hasta nuestros días, ha sido gracias a la tarea de miles de copistas y escribas que han ido copiando en papiros, pergaminos, vitelas y papeles los textos a su vez copiados por otros tantos antes que ellos. Los libros han sido escritos una y otra vez por miles de manos, atravesando siglos y sorteando todo tipo de peligros de destrucción. Copiar un texto palabra por palabra ha sido una actividad relativamente común hasta mediados del siglo XV, pero desde entonces, salvo fragmentos parciales de textos, ha caído en desuso.

Los colaboradores de Time has fallen... son también una extraña forma de copista. En el caso Seltsame Sterne starren zur Erde (2016), de Emine Sevgi Özdamar, de hecho, de forma muy clara, ya que Sonia Si Ahmed ha asumido el papel de amanuense, decidiendo escribir cada ejemplar a mano ${ }^{4}$ Pero incluso aunque el resto de libros reescritos del proyecto haya pasado por la imprenta, se podrían pensar a través de la figura del copista. Lo que tienen en común el escribiente y el artista de Time has fallen..., es que entre cada libro y su copia se dibuja un arco en el que necesariamente interviene un cuerpo. La diferencia radica en que el lapso de tiempo entre lectura y copia en el caso de Time has fallen... es mucho mayor (pero igualmente salvable, en tanto los libros han sido aprendidos de memoria).

En el breve intervalo de la lectura a la copia por parte del amanuense se filtraban toda una serie de errores: «es muy difícil copiar un texto sin cometer equivocaciones, y en abundantes páginas de los manuscritos medievales pueden verse casos de correcciones: palabras escritas sobre otras borradas; inserción en los márgenes de omisiones observadas en el texto; tachaduras de repeticiones» (De Hamel, 1999: 43). Unos se deben a la indolencia, otros al desconocimiento de la lengua, a saltos de línea involuntarios, a los cambios en las formas de escritura y ortografía, al deterioro del papel o a un dibujo de la letra ya muy gastado. Pero había otras transformaciones más insidiosas, que quizá introducía el monje escrupuloso subsanando lo que interpretaba como un error de un copista previo, bien corrigiendo al propio autor, como sugiere Stoppard en un párrafo hilarante sobre la tergiversación inevitable de la copia. (1999: 72, 73) Los cambios en este proceso de copias de copias son tan numerosos, ineludibles y constantes que Luciano Canfora ha llegado a afirmar en su libro con el elocuente título de El copista como autor (2014) que estas generaciones de copistas son los auténticos artífices de los textos de la tradición que ha logrado sobrevivir. Aquí está el nudo de la comparación entre copista y el autor de los libros de Time has fallen... que me interesa observar en detalle, de modo que se pueda rastrear un tipo muy singular de autoría involuntaria, no deliberada, en el proyecto de Mette Edvardsen.

Las alteraciones que se han producido en los libros en esta fase reciente de Time has fallen... son obviamente diferentes a las que producían los copistas medievales en los textos que reproducían. El

\footnotetext{
${ }^{4}$ Los ejemplares se han publicado con la información genérica y con 280 páginas en blanco para ser posteriormente escritas a mano por Sonia Si Ahmed.
} 
libro que se copia es el que se ha habitado en un cuerpo durante un tiempo. Así se indica en cada publicación: «Esta edición no es una reedición del texto original. Es una reescritura del texto después de un proceso de lectura, memorización y recitado, con todas las alteraciones que hayan podido ocurrir en el curso de este proceso». Esos libros, que durante un tiempo viven en los cuerpos que los han memorizado, han acompañado a sus hafices-copistas a través de diversas experiencias, han sido recitados, contados, transmitidos, olvidados parcialmente, en definitiva, apropiados.

Las transformaciones que vive el texto en su nuevo hábitat y que se ven en su vuelta al papel en la fase más reciente del proyecto son varias: por un lado, las vinculadas al proceso de aprendizaje. Algunos de los artistas involucrados en la memorización comentan que los elementos como el lugar, el tiempo atmosférico, o las anécdotas personales del día en el que aprendían el libro se han quedado fijados inevitablemente a ciertos pasajes, por ejemplo. Por otro lado, hay alteraciones que surgen de las sucesivas lecturas del texto. Los libros vivos de Time has fallen... no sólo recuerdan su texto, sino las lecturas que han hecho de él, quizá un poco a la manera de Funes el memorioso cuya memoria privilegiada le permitía «no sólo podía recordar cada hoja de cada árbol de cada monte, sino también las veces que lo había percibido o imaginado» (Borges, 1942: 75) Las lecturas afectan al libro, se van sedimentando en él, dejando una especie muy particular de subrayado y notas al margen: en el texto se anclan las situaciones de las lecturas, como por ejemplo a quién leyeron, cómo los lectores reaccionaron a ciertos pasajes, ciertos comentarios suyos tras la lectura o incluso correcciones ${ }^{5}$. Esto conlleva a veces una lectura más pausada de ciertos pasajes, o el énfasis en determinadas palabras, por ejemplo, por no hablar de un plano mucho más sutil y apenas perceptible, como es el flujo de imágenes, ideas y afectos que se generan en el libro vivo en relación a su memoria de las lecturas previas. Por último, vinculadas a los ritmos particulares del cuerpo que acoge el texto, a la respiración, a la cadencia de su habla, o a sus preferencias sintácticas, por ejemplo, se dan ciertas transformaciones en el texto: añadidos mínimos de una interjección, olvidos de un adverbio, lapsus y descuidos varios que merece la pena observar en detalle.

Los textos no permanecen inalterables en la memoria, sino que se reescriben constantemente cada vez que se vuelve a ellos; están sometidos a un proceso continuo de variaciones y reajustes, en el que lo recordado se anuda e integra con experiencias, imágenes y sensaciones. Esto queda muy claro en la explicación que ofrece Wouter Krokaert en su decisión de introducir imágenes en su copia de Elias, of het gevecht met de nachtegalen de Maurice Gilliams:

Hice espacio para mis propias imágenes no para ilustrar la historia o para reemplazarla con imágenes que no se pueden hacer aparecer por medio de palabras, sino porque mis propias imágenes estaban entrelazadas con las de Elias. Porque el libro no tardó en traer a la superficie memorias de experiencias personales y de esta forma es como los años de mi propia infancia se entrelazaron con los de Elias (GilliamsKrokaert, 2016: 54-55).

\footnotetext{
${ }^{5}$ El caso de una lectora de I am a cat de Soseki Natsume, de Mette Edvardsen es particularmente divertido: en el libro se habla de un gato macho de tres colores, cosa que es imposible, comentó la lectora, ya que los gatos de tres colores son siempre hembras. Desde entonces Edvardsen no puede evitar pensar en ello cada vez que lee el pasaje para alguien.
} 
En el proceso de reescritura que está teniendo lugar en el último año y medio del proyecto, se comprueba que las mayores variaciones se dan de hecho en la puntuación gráfica, como se puede observar, por ejemplo, en Against the forgetting. Selected poems de Hans Faverey, de Bruno de Wachter (2016). Debido a que en el proceso de memorización del texto fue ajustando los versos a su propio ritmo, y a que en el momento de devolverlos al papel los había hecho suyos por completo, optó por prescindir totalmente de ellos y en cambio introdujo entre cada palabra un espacio mayor o menor que podría indicar la longitud de la pausa y así reproducir su flujo cambiante de recitado.

Estas huellas (que no se promueven, ni buscan, ya que toda transcripción del libro aprendido se ha hecho sin concesiones a la creatividad, respetando rigurosamente la fidelidad al texto aprendido) son valiosas en los libros de Time has fallen..., ya que son las que permiten percibir la vida de ese libro, sus transformaciones en el contacto con un cuerpo vivo que se inserta clandestinamente entre sus líneas, en sus ritmos, en ciertos giros y expresiones. El interés de estas huellas no reside, desde mi punto de vista, en el posible carácter psicológico de las ansiedades, obsesiones o miedos singulares de una persona, como signos que permiten ahondar en la psique y los procedimientos de olvido, recuerdo y construcción de los artistas que participan en el proyecto de Time has fallen... No se trata de tomar un libro como medio o excusa para, a través de él, inferir una psique. Las huellas permiten tomar conciencia de dos dimensiones de la literatura hasta la fecha prácticamente ignoradas: una, la propia vida del libro a través de sus lecturas y apropiaciones, su historia singular en los sucesivos lapsos de encarnación hasta que vuelve a su silencio y a la (nueva) estabilidad en una estantería. Es la historia de dimensión de la literatura a la que me he referido con la figura del hafiz, narración que usualmente se pasa por alto por escurridiza y difícil de apresar con nuestros esquemas de pensamiento occidentales; y que lógicamente son una de las preocupaciones de una artista como Mette Edvardsen, con una formación en artes vivas, en prácticas basadas en el cuerpo y en el encuentro. La otra es que estas huellas permiten también asomarse a una comprensión de la autoría involuntaria muy interesante, comparable en parte a la transformación de los textos de la tradición antes de la imprenta, de copia a copia, de la forma estable e inerte que un texto parece asumir en un momento dado, a la siguiente. La suma de los lapsos de tiempo entre una y otra copia son los que acaban configurando una evolución que en parte se ha tratado de ignorar. Se han considerado errores execrables, imperfecciones que el filólogo sortea en la búsqueda del libro originario. Aquí está el núcleo de la comparación entre copista y el autor de los libros de Time has fallen... que me interesa observar en detalle, con el fin de rastrear un tipo muy singular de autoría involuntaria. Una autoría además es siempre inconclusa porque sigue operando más allá de su fijación circunstancial. De hecho, es significativo la duda que expresó Bruno de Wachter en relación a la posibilidad de publicar de nuevo su memoria de Against the forgetting: Selected poems de Hans Faverey, un año más tarde, aprovechando que había memorizado varios poemarios más. Se preguntaba si debía reproducir de nuevo los ya publicados, ya que con toda seguridad contendrían variaciones respecto a la primera edición, al haber pasado más tiempo por ellos.

Time has fallen... pone en valor justamente lo contrario de lo que buscaba el filólogo-detective sorteando imperfecciones en búsqueda del original. El libro reescrito muestra, evidencia las mínimas 
transformaciones que se han operado en el libro aprendido. Estas alteraciones introducidas en los libros devueltos al papel de Time has fallen... no son fruto de la creatividad, caprichos o mera voluntad de renovación, respuestas a una autoría con voluntad de afirmarse. Son la consecuencia en todo caso de una actitud de reconocimiento de los procesos de transformación no fomentados que suceden en la vida de los textos. Y, de hecho, al igual que los copistas medievales a partir de finales del siglo IV, todos los autores de Time has fallen... han incluido en sus libros en papel una subscriptio. Los colofones medievales podían simplemente llevar el nombre y la firma de quien la realizó, o en otras ocasiones extenderse y expresar alegría por el fin de su tarea, lamentarse de lo extenso del libro copiado o disculparse de antemano por los errores que se hubieran podido cometer en la copia, en el caso por ejemplo de copistas desconocedores del latín o de la lengua en la que el ejemplar estuviera escrito. En el caso de los epílogos de los libros reescritos de Time has fallen... sus copistas se disculpan de los posibles olvidos, avisan de los cambios que hayan podido introducir y comentan las razones de sus decisiones. Pero también, y esto es lo verdaderamente interesante, en algunos casos se apunta hacia una autoría muy particular que se filtra en el texto. Aunque la lectura de los libros haya sido la mejor posible, la más rigurosa, la memoria, el cuerpo y el tiempo de manera inevitable han operado como autoría subterránea que se extiende subrepticiamente entre las líneas del texto. El texto ya no pertenece solo a su autor primero, sino también a otro que se ha infiltrado en la copia. El Een dag in 't jaar del proyecto no es de Herman Gorter, sino «de Herman Gorter, de Johan Sonnenschein».

\section{Pierre Menard y la autoría subterránea}

Pierre Menard, personaje de ficción del famosísimo relato de Borges (1996), se propone escribir El Quijote. No transcribirlo, copiarlo, plagiarlo, ni escribir una nueva versión, sino que «su admirable ambición era producir unas páginas que coincidieran -palabra por palabra y línea por línea- con las de Miguel de Cervantes» (1942: 24) Tal y como explica Borges, su método al comienzo consistió en ser Miguel de Cervantes, lo cual implicaba «conocer bien el español, recuperar la fe católica, guerrear contra los moros o contra el turco, olvidar la historia de Europa entre los años de 1602 y 1918, ser Miguel de Cervantes» (Ibíd.) Pero, resultándole excesivamente fácil este procedimiento, decide seguir siendo quien es, un escritor del siglo $\mathrm{XX}$, y a partir de su propia experiencia, llegar a El Quijote. Consigue escribir sólo los capítulos 9, 38 y parte del 22, porque su tarea era mucho más compleja que la de Cervantes. Así lo explica Menard: «Mi complaciente precursor no rehusó la colaboración del azar: iba componiendo la obra inmortal un poco à la diable, llevado por inercias del lenguaje y de la invención. Yo he contraído el misterioso deber de reconstruir literalmente su obra espontánea» (Ibíd: 26). Reescribirlo en el siglo XX implica un trabajo que no deja nada al azar, imponerse una escritura mucho más ambigua y sutil, obligándose a veces a un trabajo irónico de defender ideas contrarias a las suyas, forzarse a trabajar con la psicología, el equívoco, o la ambigüedad.

Menard optó por destruir todo su trabajo intermedio, todos los borradores y notas y tan sólo dejar esos capítulos de El Quijote, lo que, según el relato, podía llevar a suponer que simplemente lo 
transcribió. Al igual que Menard, los autores subterráneos de Time has fallen... tampoco conservan (o no han hecho públicos junto con los libros editados) sus apuntes y anotaciones, ni los procedimientos que desarrollaron para llevar a cabo la ardua tarea de memorización. Comparando ambos textos, podría pasar como en El Quijote de Menard, que sean idénticos. Pero los procesos mentales que han llevado a optar por un giro u otro, por una expresión u otra, tienen en su segundo autor significaciones e implicaciones muy diferentes. Han tenido que diseñar sus propias formas de encontrar la lógica en una frase específica, al igual que hallar razones para una expresión ajena o arcaizante.

La autoría en el caso de Menard lleva a Borges a comprender «el Quijote final» como una especie de palimpsesto, en el que se podrían leer de forma parcial y ambigua, dos libros. Y esto es precisamente lo que ocurre con la reescritura de Monsieur Songe de Robert Pinget, llevada a cabo por Vincent Dunoyer. A diferencia de otros participantes del proyecto, que optaron por una escritura completa del texto en un documento nuevo, Vincent Dunoyer decidió insertar su lectura dentro del ejemplar mismo que tenía en sus manos. Con pegamento y tijeras, cortando y pegando como en una operación quirúrgica, hizo espacio para su libro en el propio libro de Pinget, de modo que incluyó en éste todas y cada una de las variaciones, por mínimas que fueran, respecto al texto que recordaba-. La intervención sobre el título mismo ya sugiere las complejas relaciones de subordinación y a la par de afirmación de su autoría secundaria: Monsieur Songe pasa a ser Mon Songe, que puede significar tanto «mi Songe», como «mi sueño», a la par que remite fonéticamente a «mentira» (mensonge). A este título se le añade un subtítulo: «seguido de Sosie Songe», un añadido de Vincent Dunoyer que remite tanto a su posición como reescritor del libro (el sosias, el doble de Songe), como a la sirvienta de este personaje en la novela, que se llama Sosie (sosias en francés). En uno de los epílogos más interesantes de toda la colección, Vincent Dunoyer se dedica a detallar uno por uno los lapsus y errores que ha insertado en el texto, así como a analizar su significado en lo tocante a las relaciones de poder entre Pinget, Songe, Sosie y él mismo, señalando las posiciones ambivalentes, inestables y de interdependencia entre todos ellos. Vincent en ocasiones se identifica como la sirvienta: en un punto dado Songe toma una «taza de café», que Vincent ha recordado sólo como «un café». Dunoyer sugiere que el espacio en blanco que se abre en la página con ese olvido hace las veces de una enorme nube de leche, para dictaminar con sorna: «Monsieur Songe beberá el café de ahora en adelante blanco» (Dunoyer: 2017: 126) Otras veces, en cambio, se pone del lado del autor y ante la sustitución de «reprender» por «responder» en su recuerdo, Dunoyer afirma la sumisión de Sosias (el alter-ego de Dunoyer, con quien se identifica), a la lógica del maestro, de Songe-Pinget. Quizá sea en la última nota de esta parte del libro donde se plantee de forma más clara el juego de identidades al que ha dado lugar la reescritura del libro:

Igual que el hombre retirado que invierte las imágenes o las confunde, a veces he confundido o invertido las palabras del texto original, de ahí lo inverosímil de unos pasajes que sin embargo me parecían familiares. Y he aquí que, a fin de cuentas, habiéndome creído Sosie, me he dado cuenta de que soy también un poco Monsieur Songe. ¿Sosie Songe, entonces? (Ibíd.: 132). 
En la reescritura de Monsieur Songe se hace especialmente patente la riqueza de las formas de autoría secundarias en los libros devueltos a papel. Los participantes de Time has fallen... son copistas, pero dignificados en una posición de autoría ahora incontestable, una autoría involuntaria que se ha ido infiltrando en cada uno de los libros aprendidos, mezcla del azar, del tiempo, de la singularidad del cuerpo y del trabajo de la memoria. Lo que evidencian las reescrituras, los libros «de de» (que han vuelto de nuevo a una la estabilidad del papel), es el intervalo de tiempo al que los libros han despertado, el vasto mundo de sus vidas en los cuerpos en los que habitan.

La operación de devolver los libros vividos a papel permite percibir un rastro de los procesos por lo general invisibles de la literatura que se mueven entre lo fantasmal y lo objetual. Retomo las palabras del profesor de literatura cimeria Uzzi-Tuzii en Si una noche de invierno un viajero, en las que sugiere que la lectura comienza en el libro, pero siempre se despliega en otras regiones más allá, quizá después de la última página:

Leer [...] es siempre esto: hay una cosa que está ahí, una cosa hecha de escritura, un objeto sólido, material, que no se puede cambiar, y a través de esta cosa nos enfrentamos con alguna otra que no está presente, alguna otra que forma parte del mundo inmaterial, invisible, porque es sólo pensable, imaginable. (Calvino, 1980: 33)

Ludmila, la protagonista femenina del libro, añade: «...O que no está presente porque aún no existe, algo deseado, temido, posible o imposible». (Ibíd.) En este último caso se afirma no tanto la deriva hacia la muerte de los libros (sugerida por Uzzi-Tuzii en otras páginas de la novela), como sobre todo su existencia en los cuerpos. Lo que hacen visibles los lapsus y mínimos errores de los libros reescritos de Time has fallen... es precisamente las vidas que han vivido. Lo que señalan es el intervalo de vida por la que el texto pasa entre su dos existencia inertes en papel, la original y la reescritura. En este segundo libro se puede acceder de manera oblicua al espacio entre, entre dos libros, entre dos estabilidades, esa zona opaca, intermedia y generalmente inaccesible.

Time has fallen... es un proyecto bello en su economía de medios y simplicidad: memorizar libros y luego llevarlos a papel desde el recuerdo. Pero esta sencillez alcanza un gran impacto porque sacude la estabilidad y los principios fundamentales de unicidad y autenticidad del origen en el que todavía se basa no sólo la tradición escrita, sino nuestra cultura en general. El gesto de ser fiel no al texto en términos de identidad, sino a su vida en contacto con un cuerpo, es un gesto liberador, que permite la diferencia, que rompe con una pureza conseguida a base de la destrucción de toda ambivalencia, de toda equivocidad, de todo incremento, de todo lo que resulta excesivo, esto es, del cuerpo para la letra y de las autorías que se enredan subrepticiamente entre las líneas. En el caso de los libros de Time has fallen... ocurre algo similar a la lectura ficcional de El Quijote de Menard, una lectura en la que se lee siempre mucho más de lo que encontraríamos en un libro convencional de un solo autor. La propuesta de Time has fallen..., tan imaginativa como las mejores ficciones de Borges, «puebla de aventuras los libros más calmosos» (Borges, 1942: 29) 
Tropelías. Revista de Teoría de la Literatura y Literatura Comparada, número extraordinario 2 (2017) 461

Autorías subterráneas. Texto, cuerpo y vida en Time has fallen asleep in the afternoon sunshine

\section{Referencias bibliográficas}

BARTHES, R. (1974): «Texto (teoría del)», en Variaciones sobre la escritura. Barcelona, Paidós, 2002.

BoRgES, J. L. (1942): Ficciones. Madrid, Alianza Editorial, 1998. (1983): Cuentos completos. Barcelona, Lumen, 2011.

Borges, J. L. - Bioy Casares, A. (1967): Crónicas de Bustos Domecq. Barcelona, Losada, 1998.

CALvino, I. (1979): Si una noche de invierno un viajero. Barcelona, Bruguera, 1980.

CANFORA, L. (2002): El copista como autor. Salamanca, Delirio, 2014.

DE HAMEl, Ch. (1992): Copistas e iluminadores. Madrid, Akal, 1999.

DunOyer, V. - Pinget, R. (2017): Mon Songe. Bruselas, Time has fallen asleep in the afternoon sunshine.

KROKAERT, W. - GILliAMS, M. (2016): Elias of het gevecht met de nachtegalen- Bruselas, Time has fallen asleep in the afternoon sunshine.

MANGuel, A. (1996): Una historia de la lectura. Buenos Aires, Siglo XXI, 2014.

ÖZDAMAR, E. S. - AHMED, S.S. (2016) Seltsame Sterne starren zur Erde. Bruselas, Time has fallen asleep in the afternoon sunshine.

RoussEAU, J. J. - LUDI, S. (2016): Rêveries du promeneur solitaire. Bruselas, Time has fallen asleep in the afternoon sunshine.

STOPPARD, T. (1997): The Invention of Love. Nueva York, Grove Press. 